\title{
Modelo de observatorio de prensa y política: Ecuador 2009-2011*
}

\author{
Francisco Rodríguez y Katherine Rivadeneira ${ }^{* *}$
}

\section{Prensa y oposición política}

Allí donde los gobiernos son parte de los poderes económicos, y por consiguiente también de las grandes empresas de la comunicación y la información, los medios serán partidarios del gobierno; pero, donde los gobiernos en cierto modo resisten o en cierta medida se enfrentan a los poderes económicos, financieros y empresariales, los medios serán partidarios de estos últimos y serán opositores a los gobiernos. De la misma manera que los mass-media tuvieron una influencia decisiva en la consolidación del proyecto neoliberal desde la década de los 70 y 80 en América Latina, igualmente desplegarán un extraordinario poder de oposición en contra de los gobiernos anti-neoliberales, que durante la última década se instalan en varios países latinoamericanos. Está demostrado que el control por parte de las élites de los medios de comunicación ha sido constantemente usada para manipular la opinión pública, desacreditar las alternativas políticas y legitimar la represión de las organizaciones populares. Esta tendencia histórica se ha intensificado fuertemente durante la era neoliberal con la penetración del capital mediático transnacional. "Mientras que los latifundios mediáticos han ejercido su poder en activa oposición a los gobiernos antineoliberales, los mass media transnacionales y las instituciones educativas bajo el control privado de las élites (...) han debilitado las bases del pensar crítico y reproducido los principales núcleos de la dominación capitalista neoliberal" (I. Ramonet, 2011:55).

Hasta ahora el poder de los medios no consistía tanto en su propio poder cuanto en el hecho de encontrarse estrechamente articulados e identificados con los otros poderes políticos y económicos. En la nueva guerra ideológica que impone la globalización los medios actúan como aparatos ideológicos y dejan de comportarse como organismos de información y comunicación para desempeñarse como verdaderos partidos políticos: "no reivindican el derecho a la crítica, pero se erigen en oposición ideológica; su verdadera misión es contener las reivindicaciones populares" (Ibíd.).

\footnotetext{
* Este estudio es parte de una investigación, dirigida por J. Sánchez Parga sobre Nuevas formas de oposición política: medios y conflictos sociales: Ecuador 2009-2011.

** Egresados de Comunicación Social, Universidad Politécnica Salesiana, UPS.
} 
La oposición política de El Comercio de Lima a la candidatura de Humala influirá tanto en su campaña electoral como en su victoria para la elección presidencial y la reacción negativa de las bolsas. En Ecuador la oposición política de la prensa al Referéndum organizado por iniciativa del gobierno durante los 15 días anteriores a la consulta (16-30 de abril 2011) fue tan intensa como generalizada en los cuatro periódicos de distribución nacional. ${ }^{1}$

La fuerza de los medios consiste en que actúan políticamente al margen de las instituciones democráticas, sin asumir responsabilidades políticas, exigiendo cuentas a todo el mundo sin rendir cuentas a nadie, "hasta el punto que no es falso afirmar que los medias dominantes plantean en la actualidad un grave problema a la democracia: lejos de contribuir a ampliar el campo democrático trabajan, por el contrario, a restringirlo y minarlo" (p. 45).

En la medida en que han adquirido mayor poder económico y mayor influencia política los medios de comunicación han dejado de ser un instrumento o arma de la oposición política para actuar ellos mismos políticamente y convertirse en opositores políticos. "Y si continúan a reclamarse como un cuarto poder es porque desde ahora se asocian a los otros poderes dominantes: político, económico, financiero. Y porque no tienen el más mínimo escrúpulo en dominar a su vez a los ciudadanos como poder suplementario y como poder mediático". ${ }^{2}$

La oposición de los medios en Ecuador al gobierno de Correa no es más que una de las batallas de la guerra mediática contra las democracias progresistas o anti-neoliberales. "En Venezuela, en Ecuador, en Argentina y en otros Estados donde la oposición conservadora ha sido batida en elecciones democráticas, los principales grupos de prensa, de radio y televisión han desencadenado una verdadera guerra mediática contra la legitimidad de los nuevos presidentes, respectivamente, Hugo Chávez, Rafael Correa, Evo Morales, Cristina Fernández" (p. 52). Cuando dejan de ser instrumento de la oposición y se constituyen como un poder asociado a ella pero independiente, los medios se convierten en lo que Ramonet llama quinto poder. ${ }^{3}$

1 Cfr. Deslindes. Las fronteras de la prensa escrita, Boletín de coyuntura n. 4, IAEN, Quito, 2011.

2 Ignacio Ramonet, L'Explosion du journalisme. Des médias de masse à la masse des médias, Galilée, Paris, 2011:52.

3 Cfr. I. Ramonet, "Un crime parfait", Le Monde Diplomatique, juin 2002; "Le cinquième pouvoir", Le Monde Diplomatique, octubre 2003. 
Los medios de comunicación poseen un modo propio de producir oposición política. Esta específica producción mediática de oposición política será particular no solo a cada uno de los medios, ya sea prensa escrita, radio o televisión, sino incluso a cada uno de los géneros periodísticos. El modo de producir oposición política por medio de la publicación de noticias se presenta muy variado: por ejemplo, la compra de una casa en Bélgica por el presidente Correa aparece como noticia en una pequeña viñeta en la primera página del diario El Comercio, pero el diario Hoy la transforma en escándalo político al editarla ampliada casi en la mitad de su primera página.

La misma oposición política practica un periódico que regularmente entrevista a enemigos del gobierno y del Presidente, o radios y canales de televisión que entrevistan a representantes del gobierno cuestionándolo o criticándolo. También el modo de producir un reportaje se presta a un ejercicio de oposición política, cuando la información es parcial o tendenciosa. Incluso, o sobre todo, las secciones humorísticas de los medios o caricaturas periodísticas se prestan a un ilimitado ejercicio de oposición política recurriendo a la burla, el ridículo y la ironía, tanto más acerbas cuanto más personalizadas.

Aunque no se pueda atribuir a los medios la causa de la "devastación" de los principios y valores de la democracia, no cabe duda que, tanto en su ejercicio de oposición política como en uso de aparatos ideológicos de los gobiernos, han contribuido poderosamente a la deslegitimación de dichos valores y principios democráticos; sobre todo haciendo público su trastrocamiento: "el principio de opacidad es indispensable para la democracia", justificando así la opacidad que rige el funcionamiento de los mercados y las finanzas; "en las relaciones internacionales el secreto y la hipocresía son indispensables"; y con las mismas razones que elogian la no-transparencia en la política atacan lo que llaman "la tiranía de la transparencia". ${ }^{4}$

La oposición política de los medios constituye un factor decisivo para atizar un ambiente de crispación social, el cual puede recalentarse todavía más, cuando los medios se enfrentan a proyectos de ley gubernamentales o iniciativas legislativas tendientes a regularlos o limitar su excesiva politización. Tal situación se habría producido en Ecuador en el período anterior al 30 de septiembre

4 Pierre Rousselin, "La tyranie de la transparence", Le Figaro, 29 novembre 2010; Cfr. I Ramonet, 2011:92. 
de 2010, fecha de un intentona golpista contra el presidente Correa, cuando un recrudecimiento de la conflictividad social se encontró amplificada por la oposición mediática el gobierno. Que "los medios conspiren constantemente", generando situaciones como la de Ecuador es un hecho probado en ocasiones recientes y en otros países latinoamericanos. ${ }^{5}$

Los medios han dejado de ser únicamente tribuna para los políticos y su oposición al gobierno; hoy los mismos medios son actores de oposición política y producen oposición gubernamental en aquellas democracias donde los gobiernos se oponen a los intereses y fuerzas empresariales y financieras de los medios y de los grupos y sectores sociales a los que representan.

En esta "guerra mediática" participan también los gobiernos con sus propios recursos radiales, televisivos y periodísticos, con "cadenas radiales" y la misma presencia de los gobernantes y del presidente en programas semanales, como es el caso en Venezuela y en Ecuador. Este fenómeno tiene lugar precisamente en el contexto de aquellos gobiernos contra-neoliberales, que con sus políticas y programas tienden a reconvertir dos décadas de procesos e institucionalizaciones neoliberales.

La prensa escrita, de manera particular, en todo el mundo y desde hace más de una década ha servido de soporte mediático para la construcción del discurso neoliberal, pero en la actualidad sus posicionamientos políticos se elaboran de manera más evidente, radical y violenta con la manipulación de la opinión pública, la naturalización de la economía capitalista y sobre todo de la falsificación periodística de los hechos y discursos, poniendo en práctica lo que ya Foucault había advertido: "son los periodistas que hacen existir un "hecho bruto" como acontecimiento. El acontecimiento no es un hecho sino su verbalización o puesta en palabra mediática". ${ }^{6}$

La construcción del discurso mediático y la puesta en palabra de su oposición política se elabora en base a los diferentes géneros o modos de producción periodística: la noticia, el reportaje, la editorial y las columnas de opinión. La actuación periodística tanto como la política adopta características diferentes en cada uno de estos "actos de prensa".

$5 \quad$ Cfr. Le Monde Diplomatique en español, Valencia, enero 2011.

6 Cfr. Thierry Guilbert, L'évidence du discours neoliberal. Analyse dans la presse écrite, Edit. Du Croquant, Bellecombe-en-Bauges, 2001. 


\section{1. “Actos de prensa” y oposición política}

Inspirados en la terminología de Bourdieu, se consideran "actos de prensa" los diferentes "hechos periodísticos" expresados en los textos de un diario bajo la forma de sus diferentes géneros periodísticos: la noticia, el reportaje, la entrevista, la opinión, el editorial, la caricatura o viñeta de humor... Se trata de diferentes modos de producción periodística y también de la construcción mediática de su oposición política. Pero en cuanto "actos de prensa" se trata también de su particular eficacia y efecto mediáticos y políticos.

Para construir un modelo de observatorio sobre prensa y política se han tomado como fuente de información dos periódicos de Guayaquil: El Universo y Expreso, y dos periódicos de Quito: El Comercio y Hoy. Se trata de los periódicos más grandes, de mayor tiraje y cobertura nacional. Se han tomado como indicadores cinco "actos de prensa": noticias, reportajes, editoriales, entrevistas y opinión; $y$, en referencia a la "oposición política", tres variables han sido definidas: en oposición al presidente, al Gobierno, y a políticas gubernamentales. En cuanto al período de base estudiado se han tomado los dos primeros años del gobierno de Correa, a partir de su elección bajo la nueva Constitución en abril del 2009, hasta abril de 2011 antes del Referéndum o Consulta organizada por el Gobierno.

\section{“Actos de prensa” y oposición política: abril 2009 - abril 2011}

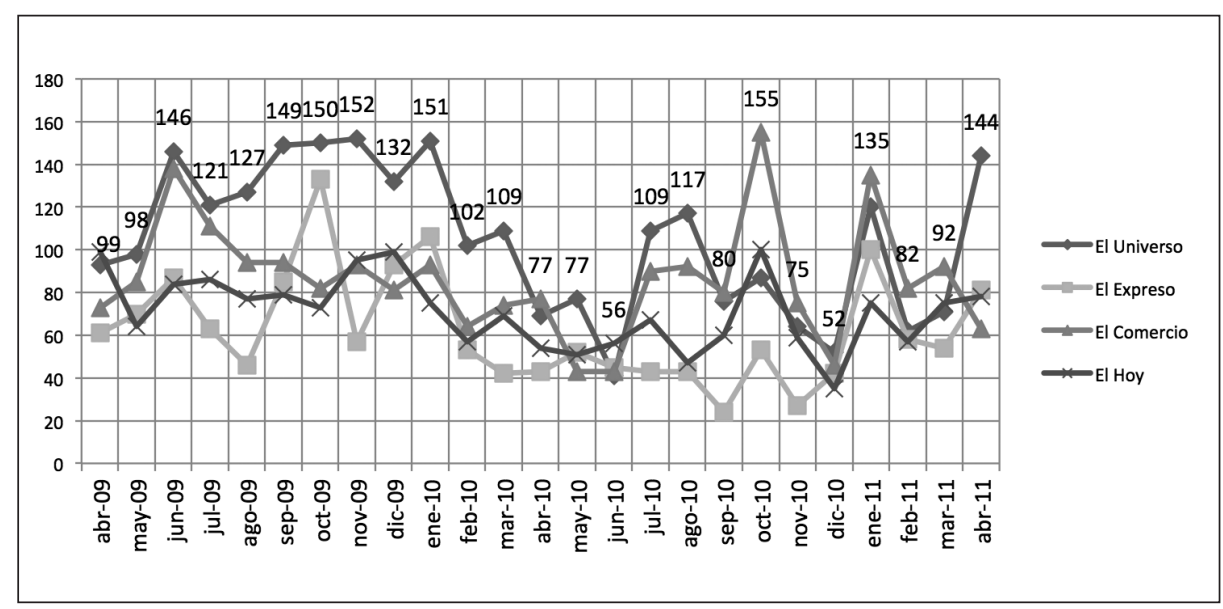

Fuente: Base de datos del Observatorio de Prensa y Política, UPS. 
Los "actos de prensa" en oposición al gobierno en general son más numerosos que aquellos referidos al presidente y a políticas gubernamentales. La oposición al Gobierno se cifra sobre todo en las reformas y cambios institucionales (económica, tributaria o fiscal, judicial, educativa, administrativa...); en reformas particulares (ley de aguas, minería, ley de prensa...). La oposición al presidente tiene por objeto traslucir el ejercicio autoritario del Gobierno y el autoritarismo en sus formas de ejercerlo.

El principal dato sobre las frecuencias y evolución anual de los actos de prensa en oposición política es su irregularidad u oscilaciones mensuales, lo cual significa que las frecuencias estarían más bien condicionadas no tanto por los criterios de la prensa cuanto por coyunturas políticas marcadas por las iniciativas y actuaciones del presidente, del Gobierno o de sus políticas gubernamentales.

“Actos de prensa”: referentes de oposición política: abril 2009 - marzo 2010

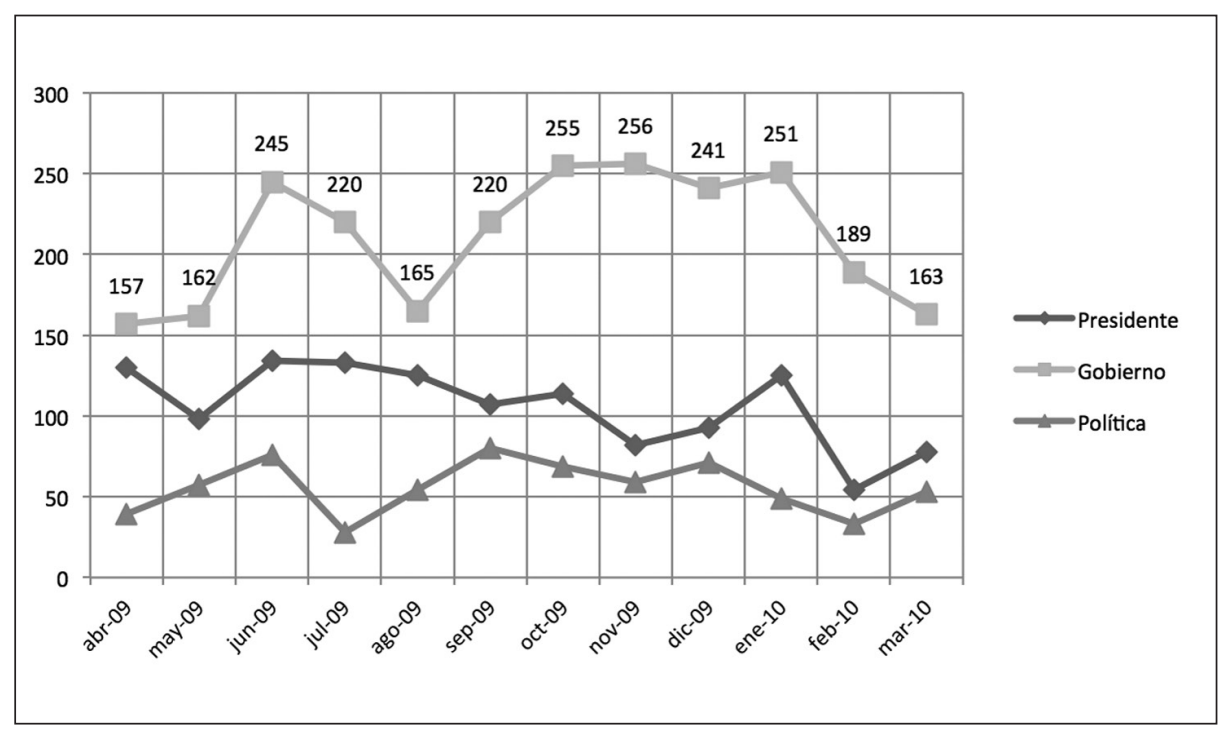

Fuente: Base de datos del Observatorio de Prensa y Política, UPS.

Sumados los actos de prensa de los cuatro diarios. 
“Actos de prensa": referentes de oposición política: abril 2010 - abril 2011

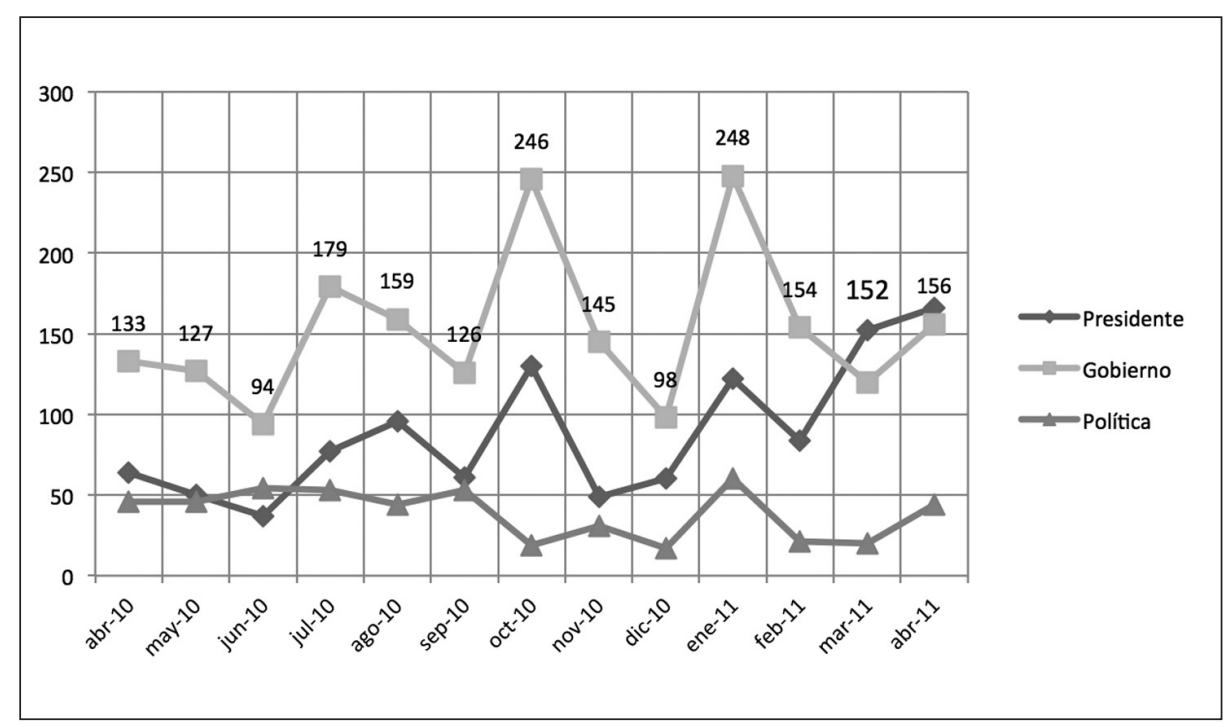

Fuente: Base de datos del Observatorio de Prensa y Política, UPS.

Sumados los actos de prensa de los cuatro diarios.

\section{a. La noticia}

El "acto" o género periodístico de mayor cobertura en un diario, y en particular dominante como oposición política, es la noticia, cuya mayor frecuencia expresa el género periodístico predominante de un diario, pero que también responde a su desdoblamiento como titular de portada, primera página, donde se marca su importancia mediático-política, y su desarrollo en las páginas interiores. Son las noticias las que con frecuencia sirven de soporte periodístico para expresar la oposición política. Sus frecuencias se presentan también con las mayores alternancias y oscilaciones. 
Noticia y oposición política: abril 2009 - abril 2011

\begin{tabular}{|l|c|c|c|c|}
\hline \multicolumn{1}{|c|}{ Diario } & Presidente & Gobierno & Políticas & Total \\
\hline El Universo & $329-26.51 \%$ & $633-51.00 \%$ & $279-22.48 \%$ & $1241-100 \%$ \\
\hline El Expreso & $162-25.96 \%$ & $212-33.97 \%$ & $250-40.06 \%$ & $624-100 \%$ \\
\hline El Comercio & $295-46.09 \%$ & $320-50 \%$ & $25-3.90 \%$ & $640-100 \%$ \\
\hline El Hoy & $320-52.20 \%$ & $268-43.71 \%$ & $25-4.07 \%$ & $613-100 \%$ \\
\hline
\end{tabular}

Fuente: Base de datos del Observatorio de Prensa y Política, UPS.

Noticia y oposición política: abril 2009 -marzo 2010

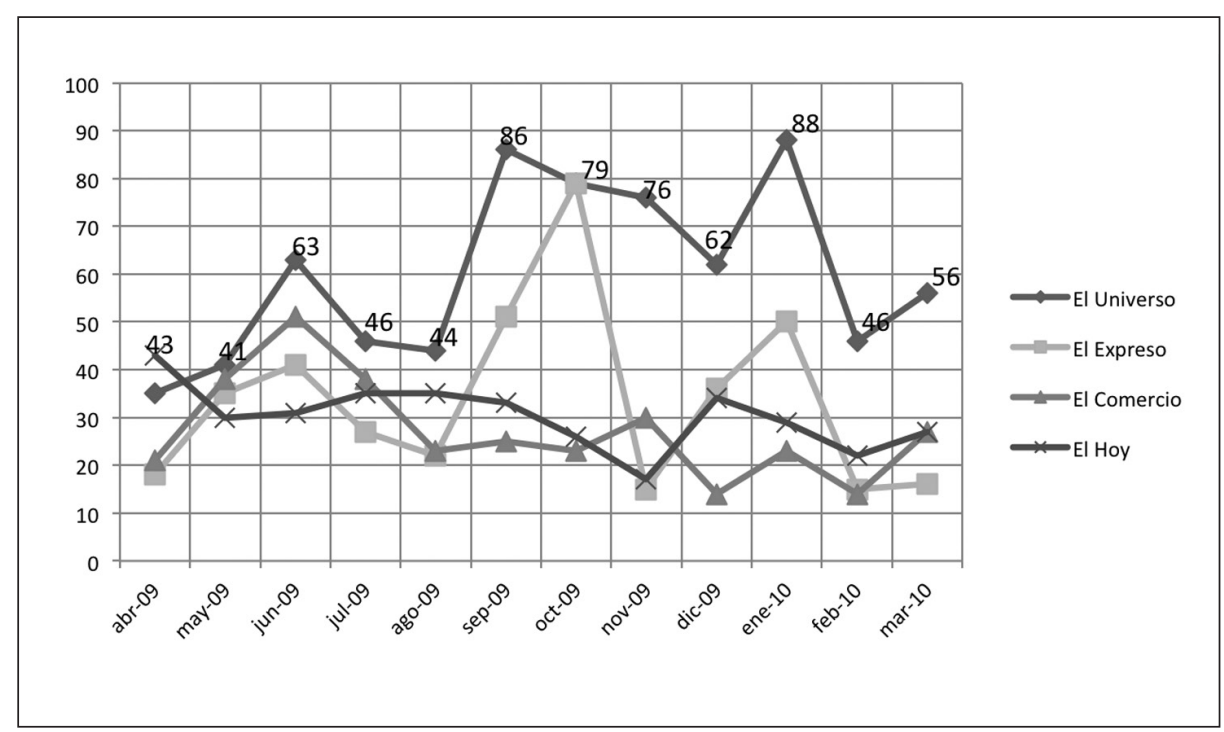

Fuente: Base de datos del Observatorio de Prensa y Política, UPS. 
Noticia y oposición política: abril 2010 -abril 2011

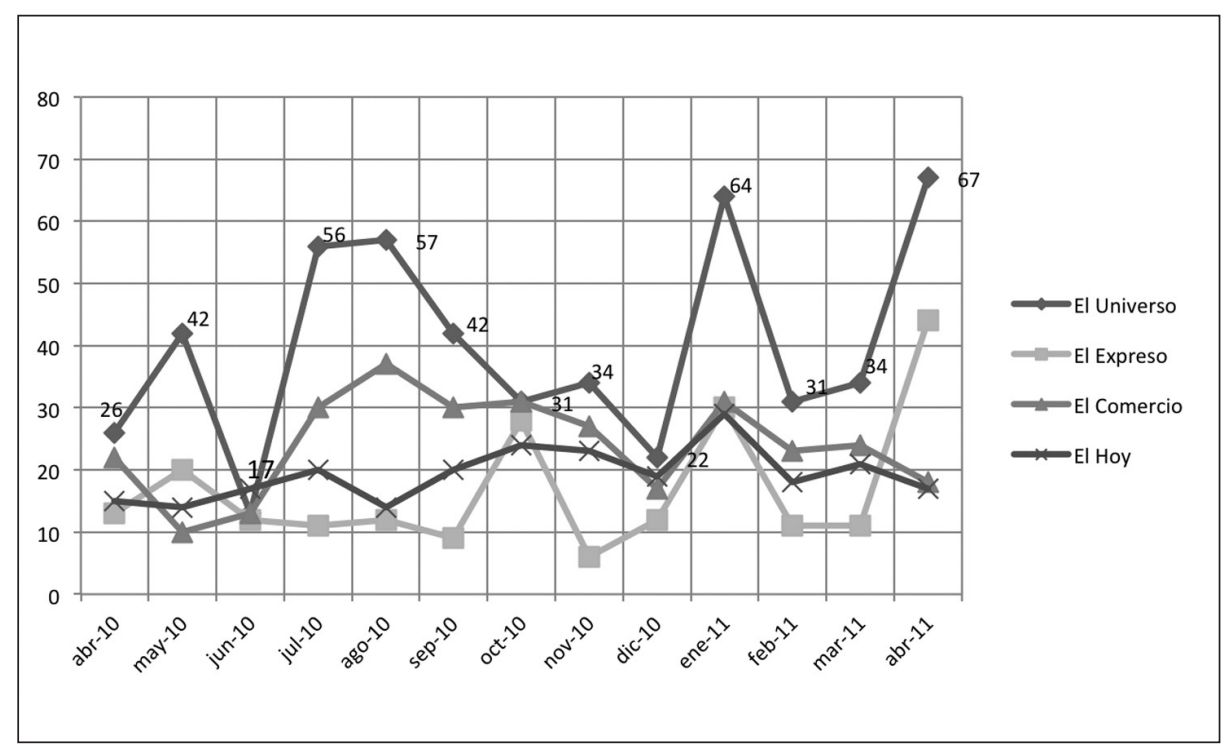

Fuente: Base de datos del Observatorio de Prensa y Política, UPS.

En la evolución de las frecuencias de noticias en oposición política durante el período de abril 2009 a marzo 2011 hay una disminución del número de noticias en el segundo año respecto del primero, pero aumenta el porcentaje de noticias en oposición al presidente, mientras que disminuyen las noticias en oposición a las políticas gubernamentales.

\section{b. La opinión}

Aunque ya la producción mediática de la noticia sirve de soporte a opiniones y mediatiza las opiniones del periódico y del periodista, desde el titular hasta su desarrollo y comentarios, las columnas de opinión representan una elaboración más analítica y crítica y sobre todo un posicionamiento de intereses entorno a los hechos. En este sentido es en la página de opiniones donde el periódico pretende desempeñar un ejercicio de autoridad pública y sobre todo define mejor sus posicionamientos y oposiciones políticas. 
Opinión y oposición política: abril 2009 -abril 2011

\begin{tabular}{|l|c|c|c|c|}
\hline \multicolumn{1}{|c|}{ Diario } & Presidente & Gobierno & Políticas & Total \\
\hline El Universo & $329-34.56 \%$ & $446-46.85 \%$ & $177-18.59 \%$ & $952-100 \%$ \\
\hline El Expreso & $196-26.63 \%$ & $425-57.74 \%$ & $115-15.63 \%$ & $736-100 \%$ \\
\hline El Comercio & $200-18.96 \%$ & $830-78.67 \%$ & $25-2.37 \%$ & $1055-100 \%$ \\
\hline El Hoy & $218-28.57 \%$ & $440-62.65 \%$ & $67-8.78 \%$ & $763-100 \%$ \\
\hline
\end{tabular}

Fuente: Base de datos del Observatorio de Prensa y Política, UPS.

\section{Opinión y oposición política: abril 2009-marzo 2010}

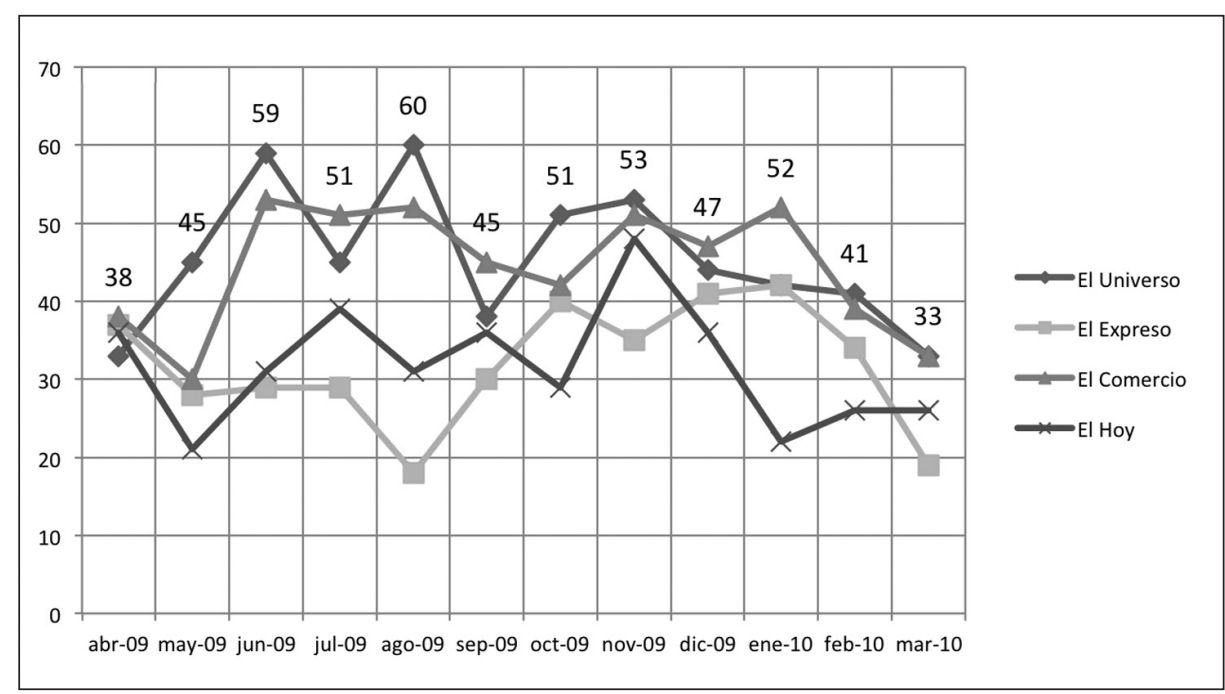

Fuente: Base de datos del Observatorio de Prensa y Política, UPS. 
Opinión y oposición política: abril 2010 -abril 2011

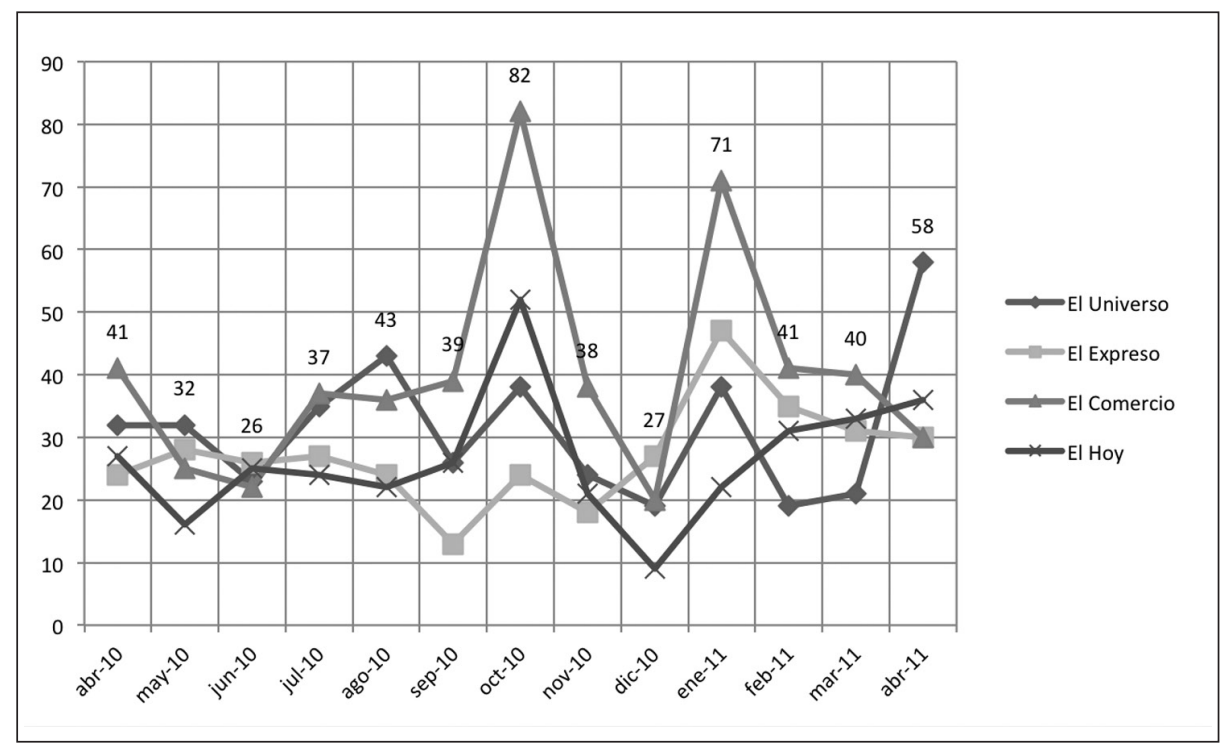

Fuente: Base de datos del Observatorio de Prensa y Política, UPS.

Cuando se comparan las frecuencias de las noticias y de las opiniones en su oposición política se observa que estas se refieren en un porcentaje mucho mayor que aquellas al presidente y en un porcentaje mucho menor a las políticas gubernamentales.

\section{c. El Editorial}

El editorial es el género periodístico que representa la opinión de la dirección del periódico en cada diario, y por consiguiente el que presenta la menor frecuencia respecto de noticias o columnas de opinión, pero también el que más define los posicionamientos políticos del periódico. 
Editorial y oposición política: abril 2009 - abril 2011

\begin{tabular}{|l|c|c|c|c|}
\hline \multicolumn{1}{|c|}{ Diario } & Presidente & Gobierno & Políticas & Total \\
\hline El Universo & $54-16.93 \%$ & $191-59.87 \%$ & $74-23.20 \%$ & $319-100 \%$ \\
\hline El Expreso & $21-17.80 \%$ & $53-44.92 \%$ & $44-37.29 \%$ & $118-100 \%$ \\
\hline El Comercio & $28-13.08 \%$ & $172-80.37 \%$ & $14-6.54 \%$ & $214-100 \%$ \\
\hline El Hoy & $22-12.22 \%$ & $141-78.33 \%$ & $17-9.44 \%$ & $180-100 \%$ \\
\hline
\end{tabular}

Fuente: Base de datos del Observatorio de Prensa y Política, UPS.

\section{Editorial y oposición política: abril 2009 -marzo 2010}

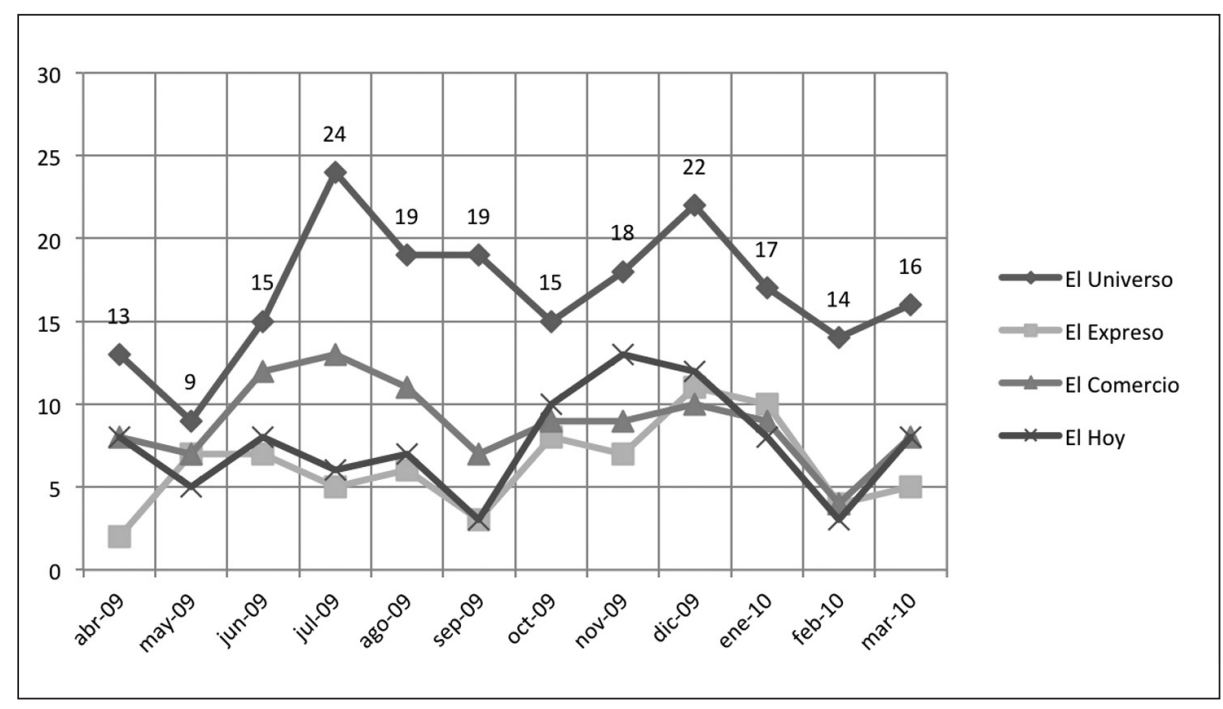

Fuente: Base de datos del Observatorio de Prensa y Política, UPS. 
Editorial y oposición política: abril 2010 -abril 2011

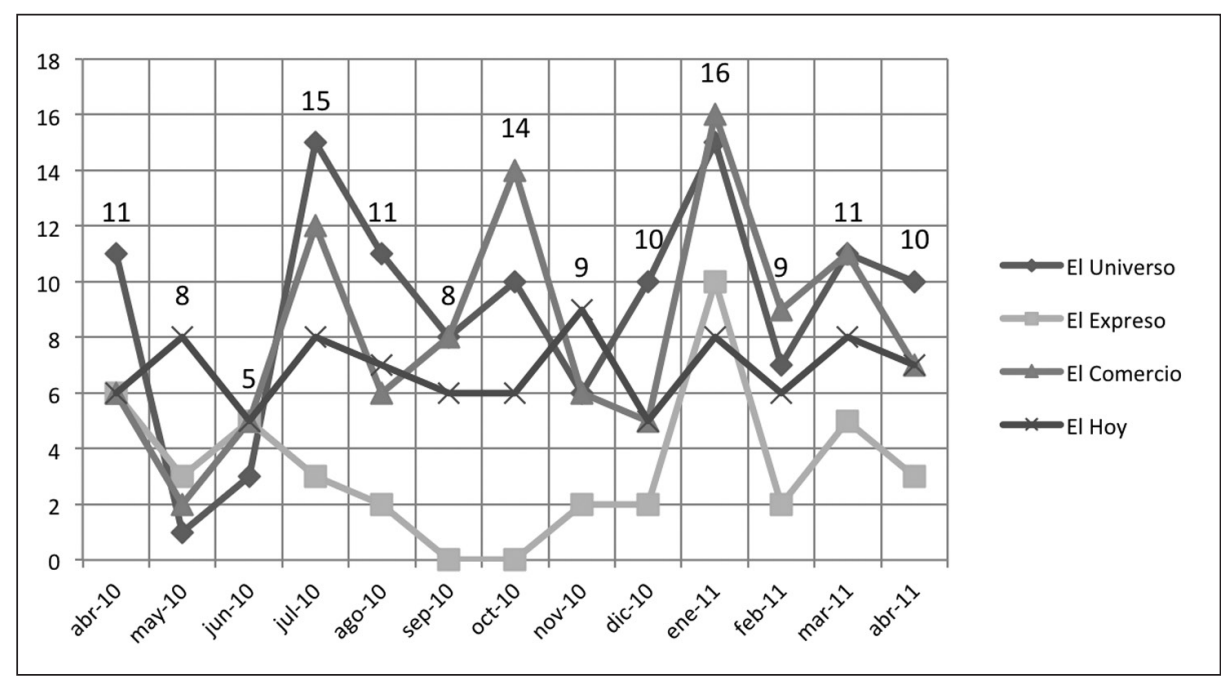

Fuente: Base de datos del Observatorio de Prensa y Política, UPS.

\section{d. Reportaje y Entrevista}

El reportaje y la entrevista son los dos géneros periodísticos menos habituales en los diarios (poco frecuentes en el caso ecuatoriano), pero por eso mismo adquieren una particular importancia, cuando responden a posicionamientos políticos, y sobre todo a una oposición política, ya que en ellos se expresa mucho más que en las noticias e incluso las columnas de opinión las disposiciones políticas de los periodistas y del mismo medio.

Reportaje y oposición política: abril 2009 - abril 2011

\begin{tabular}{|l|c|c|c|c|}
\hline \multicolumn{1}{|c|}{ Diario } & Presidente & Gobierno & Políticas & Total \\
\hline El Universo & $1-6.25 \%$ & $9-56,25 \%$ & $6-37.50 \%$ & $16-100 \%$ \\
\hline El Expreso & $2-20 \%$ & $7-70 \%$ & $1-10 \%$ & $10-100 \%$ \\
\hline El Comercio & $74-53.24 \%$ & $61-43.88 \%$ & $4-2.88 \%$ & $139-100 \%$ \\
\hline El Hoy & $56-32.75 \%$ & $101-59.06 \%$ & $14-8.19 \%$ & $171-100 \%$ \\
\hline
\end{tabular}

Fuente: Base de datos del Observatorio de Prensa y Política, UPS. 
Reportaje y oposición política: abril 2009 -marzo 2010

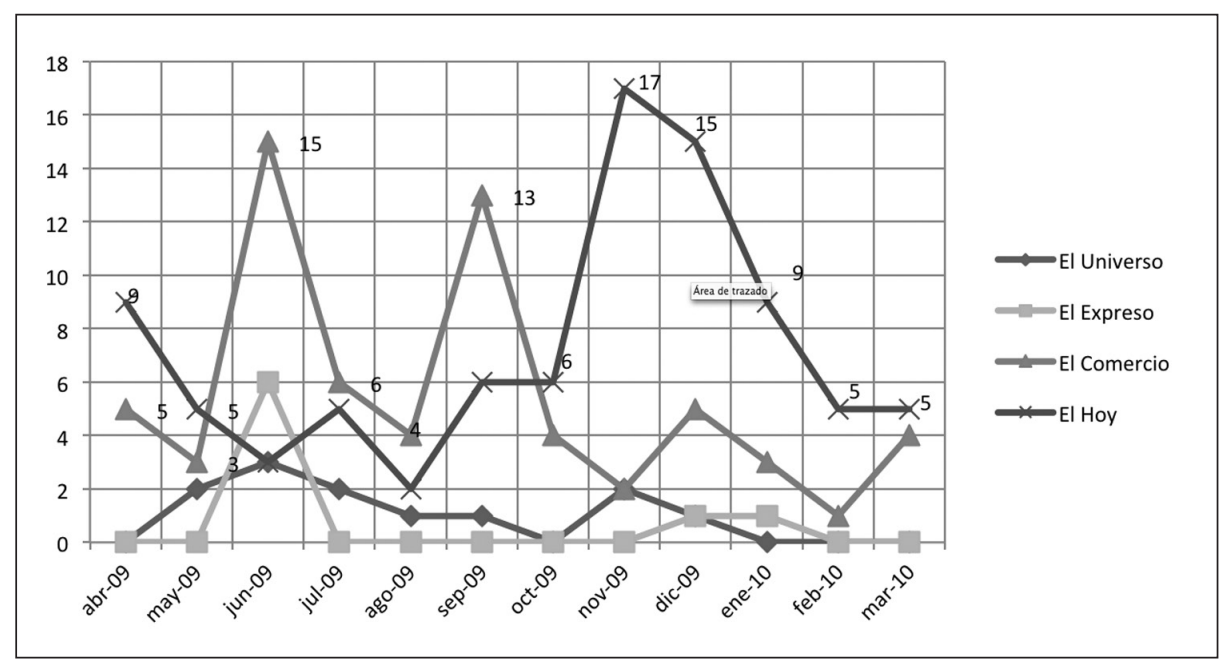

Fuente: Base de datos del Observatorio de Prensa y Política, UPS.

Reportaje y oposición política: abril 2010 -abril 2011

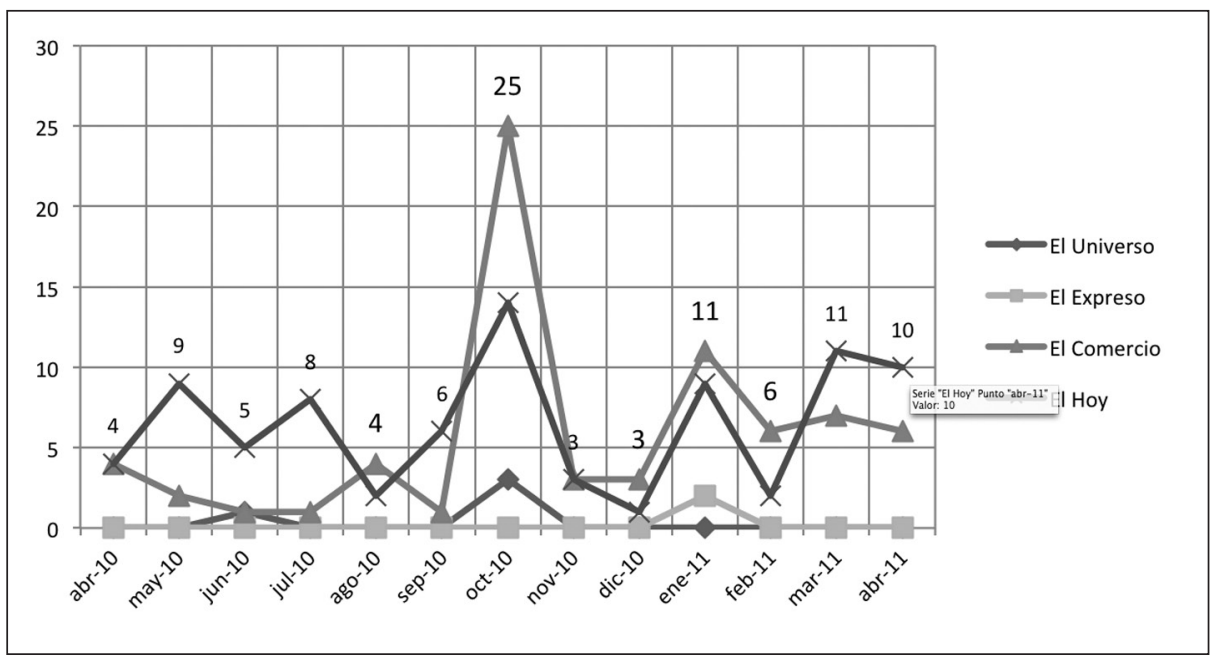

Fuente: Base de datos del Observatorio de Prensa y Política, UPS. 
Entrevista y oposición política: abril 2009 - abril 2011

\begin{tabular}{|l|c|c|c|c|}
\hline \multicolumn{1}{|c|}{ Diario } & Presidente & Gobierno & Políticas & Total \\
\hline El Universo & $17-18.68 \%$ & $63-69.23 \%$ & $11-12.09 \%$ & $91-100 \%$ \\
\hline El Expreso & $34-46.58 \%$ & $25-34.25 \%$ & $14-19.18 \%$ & $73-100 \%$ \\
\hline El Comercio & $38-35.51 \%$ & $66-61.68 \%$ & $3-2.80 \%$ & $107-100 \%$ \\
\hline El Hoy & $27-32.93 \%$ & $44-53.66 \%$ & $11-13.41 \%$ & $82-100 \%$ \\
\hline
\end{tabular}

Fuente: Base de datos del Observatorio de Prensa y Política, UPS.

\section{Entrevista y oposición política: abril 2009 -marzo 2010}

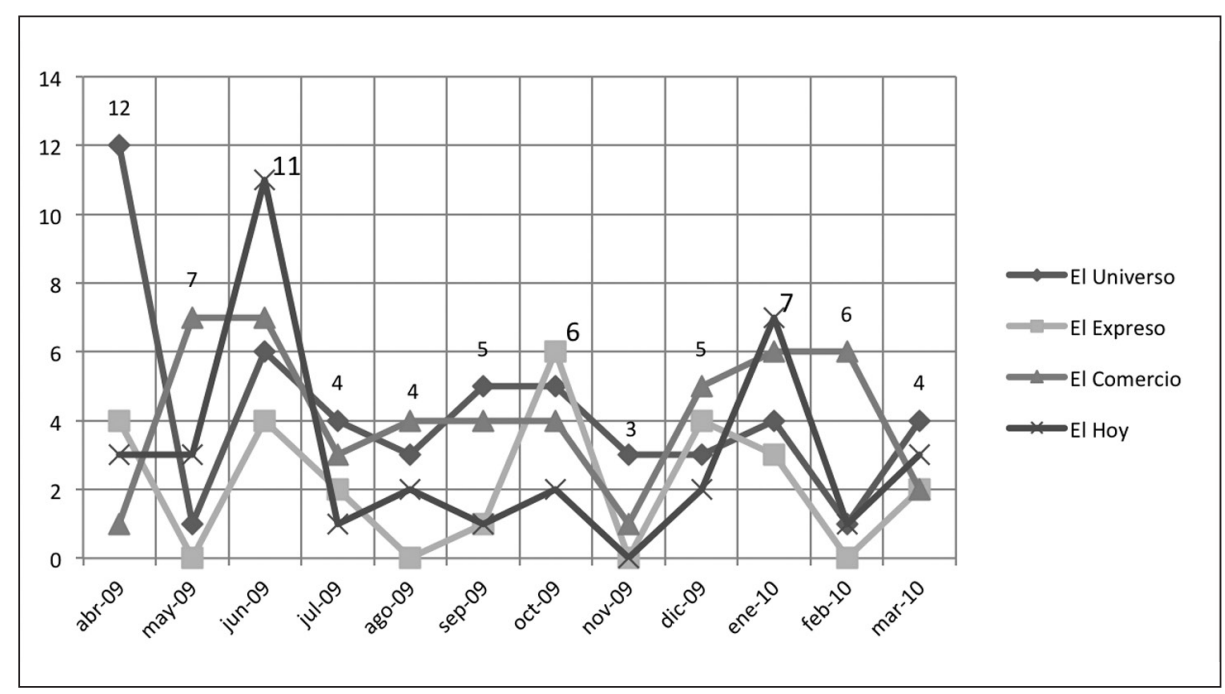

Fuente: Base de datos del Observatorio de Prensa y Política, UPS. 
Entrevista y oposición política: abril 2010 -abril 2011

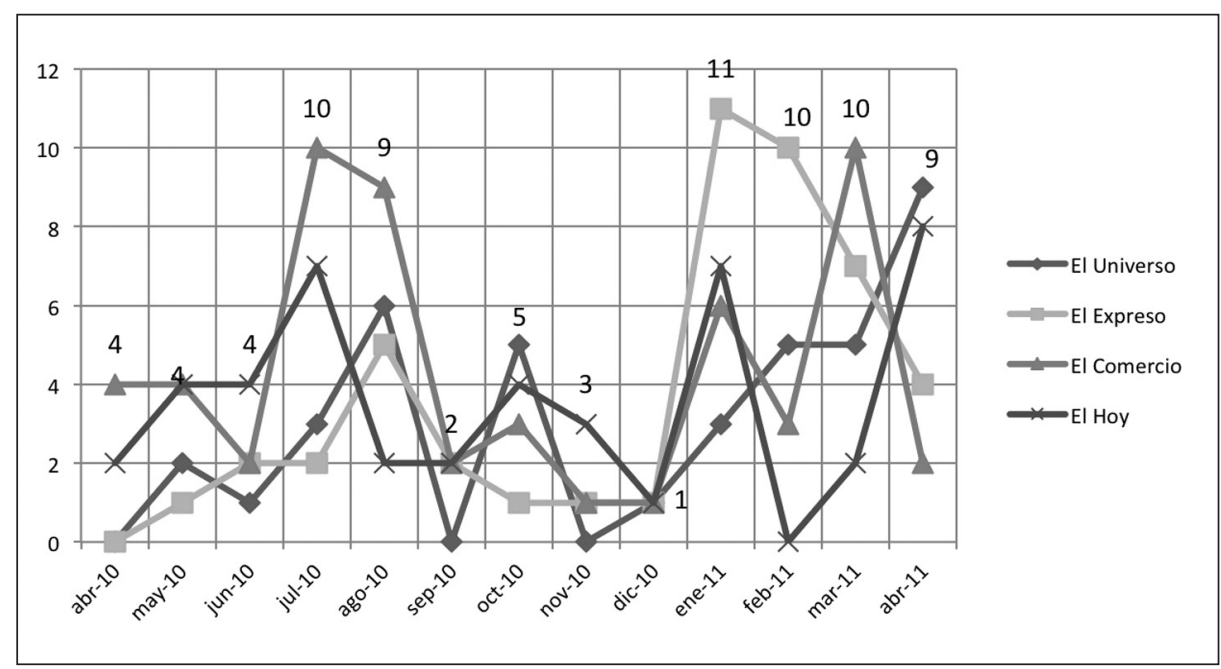

Fuente: Base de datos del Observatorio de Prensa y Política, UPS.

De la misma manera que en el caso de los dirigentes indígenas, cuanto más mostraban su oposición al gobierno tanto más eran entrevistados por los medios, lo que a su vez contribuía a reforzar su perfil de líderes, así también los principales opositores al gobierno se convierten en los sujetos más habituales de las entrevistas de los periódicos; lo que a su vez los consolida como potenciales candidatos electorales.

Otro de los "actos de prensa", que no ha sido tenido en cuenta, pero que se caracteriza por su fuerte uso político son las viñetas de humor o las caricaturas. De hecho tanto los "humoristas" de los diferentes diarios como el recurso a dicho género periodístico han dado prueba de una marcada oposición política en referencia sobre todo al presidente pero también a su gobierno. Solo este tópico merecería un tratamiento particular.

\section{Masa mediática y oposición política}

El volumen de "actos de prensa" (noticias, reportajes, editoriales, entrevistas y opiniones) en oposición política constituye una masa mediática de 
extraordinaria influencia en la opinión pública. Se trata de establecer la acumulación de esta "masa mediática" concentrada en la oposición política de los cuatro principales periódicos del país, de mayor tiraje y mayor cobertura; y por consiguiente también se trata de resaltar cómo dicha oposición política adquiere en los medios no solo una constancia sino también una realidad más efectiva de la que puede tener en otras instituciones o espacios públicos.

Para ello se han elegido los cuatro periódicos más representativos del país (El Universo, El Comercio, Hoy y Expreso), de acuerdo a su tiraje y cobertura nacional, y se ha registrado su información sobre los dos últimos años de gobierno de Rafael Correa, de acuerdo a los criterios inicialmente planteados. Esto mismo permite establecer una comparación entre ellos en referencia tanto a los indicadores de la oposición política (presidente, Gobierno, Políticas gubernamentales) así como a las variables de los actos de prensa (noticias, reportajes, editoriales, opiniones y entrevistas). Para la comparación hemos tomado los dos principales de los cuatro periódicos: El Comercio y El Universo.

La comparación de los "actos de prensa" en oposición política de ambos periódicos muestra una mayor frecuencia en El Universo (2.619) que en El Comercio (2.155) durante los dos años analizados (abril 2009-abril 2011).

Los "actos de prensa" de oposición política son más numerosos en El Universo (2.619) que en El Comercio (2.155); ambos totalizan durante los dos últimos años (abril 2009 - abril 2011) un promedio mensual de 191 "actos de prensa" en oposición política, y 6.3 diarios.

Mientras que El Universo concentra una mayor frecuencia de "actos de prensa" contra el presidente (728) que El Comercio (635), este periódico en cambio acumula más "actos de prensa" contra el Gobierno (1449) que El Universo (1344); a su vez este periódico dedica muchos más "actos de prensa" contra las políticas y programas gubernamentales (547) que El Comercio (71).

El Universo tiene más noticias (329), y más columnas de opinión (329) contra el presidente que El Comercio (295 y 200 respectivamente); y tiene más noticias (633) y muchas menos columnas de opinión contra el Gobierno (446) que El Comercio (320 y 830 respectivamente).

Así mismo los "actos de prensa" de El Universo contra las políticas y programas gubernamentales son mucho más numerosos (547) que en $E l \mathrm{Co}$ mercio (71). 
En conclusión, mientras que El Universo concentra su oposición política contra el presidente y sus políticas y programas gubernamentales, El Comercio acumula más bien su oposición política en contra del Gobierno.

Cada uno de los periódicos no solo tiene un comportamiento diferente en su oposición política en referencia al presidente, al Gobierno y a las Políticas gubernamentales en particular, sino que además ambos periódicos hacen un uso diferente de los distintos "actos de prensa" o géneros periodísticos.

El Universo tiene mayor volumen de noticias de oposición política que $E l$ Comercio y también las distribuye de manera diferente: mientras que las noticias de El Universo en oposición al presidente son ligeramente más numerosas que en El Comercio, aquellas contra el gobierno y sobre todo las políticas gubernamentales son mucho más frecuentes.

El reportaje en oposición al presidente y al Gobierno es mucho más frecuente en El Comercio que en El Universo y en contra de las políticas el número es ligeramente mayor en el El Universo.

El Comercio recurre con más frecuencia a las entrevistas de oposición al gobierno y al presidente que El Universo; mientras que en este periódico es mayor el número de las entrevistas contra las políticas.

El número de editoriales de oposición política son igualmente mucho más numerosos en El Universo que en El Comercio; sobre todo son más del doble en contra del presidente, y cuatro veces más en contra de las políticas gubernamentales. El posicionamiento político de los editoriales es muy significativo ya que expresa más que ningún otro "acto de prensa" las posiciones institucionales del periódico.

Los artículos de opinión en oposición política son igualmente numerosos en ambos periódicos, pero en contra del presidente y contra de las políticas gubernamentales son mucho más frecuentes en El Universo que en El Comercio; en este último periódico las columnas de opinión contra el Gobierno son casi el doble que en El Universo.

\section{Conclusiones}

Los medios en general y la prensa en particular han sido objeto de profundas transformaciones socio-económicas y políticas en el transcurso de las dos últimas décadas. Se trata de una nueva economía política mediática marcada en parte por su creciente empresarialización y financiarización, y en parte también 
por su extraordinario protagonismo político, que no sólo tiende a mediatizar la política y la misma democracia, sino sobre todo a convertirse de contra-poder en un potente poder político tanto como económico. Esto explica que el posicionamiento político de los medios dependa del tipo de gobierno frente al cual se sitúa de acuerdo a sus intereses.

En este sentido, principios y valores como libertad de expresión y de opinión, libertad de prensa, además de adquirir un nuevo sentido no solo se prestan a equívocos y contradicciones, sino que se convierten en armas de la misma lucha política. Tanto la "lucha de clases" como la "pugna de poderes" pasan hoy por una "lucha mediática" y el control privado y público de los medios de producción de información y opinión.

La más significativa de las conclusiones es el efecto orgánico o efecto de consenso de la prensa o del periódico en sus posicionamientos políticos. A pesar de la múltiple diversidad de editorialistas, entrevistados y columnistas o autores de opinión, todos coinciden en su oposición política y no hay opiniones favorables al Gobierno y menos al presidente. El fenómeno resulta muy singular, teniendo en cuenta que todavía en el año 2011 el presidente Correa según organismos internacionales contaba con un $64 \%$ de opinión favorable en la sociedad ecuatoriana.

Cabe suponer, según esto, que en cuanto a posicionamientos políticos hay en cada medio una opinión dominante que garantiza un consenso e impide opiniones diferentes y contrarias. Tal consenso de opinión respondería en cada medio a una composición de intereses de quienes participan y colaboran en la producción mediática; y solo cuando el consenso de cuerpo no funciona intervendría la censura interna.

La condición de opositores políticos ha hecho que escritores de editoriales o columnistas de opinión de un periódico sean publicados o invitados a escribir en otros periódicos; se trata de intelectuales, periodistas o políticos, que se vuelven transmediáticos en reconocimiento de su oposición política.

En términos cuantitativos, los "actos de prensa" en sus diferentes formas o géneros periodísticos (noticias, reportajes, entrevistas, editoriales y opinión) en oposición política al presidente, al Gobierno y a las políticas o programas gubernamentales constituyen el principal tema de los principales diarios del país (El Universo, El Comercio, Expreso, Hoy). Los cuatro periódicos El Universo y Expreso de Guayaquil, El Comercio y El Hoy de Quito, entre abril 2009 y abril 
2011, contabilizan 8.106 "actos de prensa" en oposición política, lo que supone un promedio de 324 al mes, y 10,8 diarios, entre los cuatro.

“Actos de prensa” y oposición política: abril 2009-abril 2011

\begin{tabular}{|l|c|c|c|c|c|c|}
\hline \multicolumn{1}{|c|}{ Diario } & Noticia & Reportaje & Entrevista & Editorial & Opinión & Total \\
\hline El Universo & $1241-47,38 \%$ & $16-0,61 \%$ & $91-3,47 \%$ & $319-12,18 \%$ & $952-36,35 \%$ & $2619-100 \%$ \\
\hline El Expreso & $624-39,97 \%$ & $10-0,64 \%$ & $73-4,68 \%$ & $118-7,56 \%$ & $736-47,15 \%$ & $1561-100 \%$ \\
\hline El Comercio & $640-29,70 \%$ & $139-6,45 \%$ & $107-4,97 \%$ & $214-9,93 \%$ & $1055-48,96 \%$ & $2155-100 \%$ \\
\hline El Hoy & $613-34,61 \%$ & $171-9,66 \%$ & $82-4,63 \%$ & $180-10,16 \%$ & $725-40,94 \%$ & $1771-100 \%$ \\
\hline TOTAL & $\mathbf{3 1 1 8}$ & $\mathbf{3 3 6}$ & $\mathbf{3 5 3}$ & $\mathbf{8 3 1}$ & $\mathbf{3 4 8 6}$ & $\mathbf{8 1 0 6}$ \\
\hline
\end{tabular}

Fuente: Base de datos del Observatorio de Prensa y Política, UPS.

Si se considera cuáles son los referentes de la oposición política según los diferentes medios, el porcentaje promedio contra el presidente es del $30 \%$, contra el Gobierno es del 55\% y contra las Políticas y programas gubernamentales es del $15 \%$.

“Actos de prensa": referentes de oposición política: abril 2009 - abril 2011

\begin{tabular}{|l|c|c|c|c|}
\hline \multicolumn{1}{|c|}{ Diario } & Presidente & Gobierno & Políticas & Total \\
\hline El Universo & $728-27,80 \%$ & $1344-51,32 \%$ & $547-20,89 \%$ & $2619-100 \%$ \\
\hline El Expreso & $415-27,82 \%$ & $722-48,39 \%$ & $424-28,42 \%$ & $1561-100 \%$ \\
\hline El Comercio & $635-29,47 \%$ & $1449-67,24 \%$ & $71-3,29 \%$ & $2155-100 \%$ \\
\hline El Hoy & $643-36,29 \%$ & $994-56,09 \%$ & $134-7,56 \%$ & $1771-100 \%$ \\
\hline
\end{tabular}

Fuente: Base de datos del Observatorio de Prensa y Política, UPS.

En cuanto a los contenidos, objeto de la oposición política, la prensa ha enfrentado de manera predominante al Gobierno, por sus reformas y cambios institucionales (tributaria, justicia, educación, defensa y seguridad social, leyes de minería, de aguas, de prensa...). Consecuencia de ello, en segundo lugar, ha 
confrontado directamente al presidente por su Gobierno autoritario o formas autoritarias de gobernar. En tercer lugar la oposición política de los medios se ha dirigido con menor frecuencia a las particulares políticas y programas gubernamentales. Finalmente una "pugna mediática" de denuncias y acusaciones entre el Gobierno, el presidente en particular, y la prensa ha contribuido a intensificar la oposición política.

Finalmente la prensa, sobre todo en sus principales espacios de opinión (editoriales, entrevistas, columnas o artículos de opinión) ha proporcionado espacios privilegiados a los opositores políticos, sectores y personalidades más representativos de la oposición al gobierno. 